\title{
Insulin resistance and the metabolic syndrome —or the pitfalls of epidemiology
}

\author{
J. S. Yudkin
}

Received: 8 November 2006 / Accepted: 24 April 2007 / Published online: 26 June 2007

(C) Springer-Verlag 2007

\begin{abstract}
The clustering of dyslipidaemia, hypertension and glucose intolerance, predominantly in overweight individuals, has been ascribed many names, including syndrome $\mathrm{X}$ and the metabolic syndrome. In Reaven's original description of syndrome $\mathrm{X}$, a central aetiological role was attributed to insulin resistance, and this assumption has remained as the dominant paradigm for the metabolic syndrome. There are a number of conceptual problems in such a model, particularly those arising from observations that several novel markers, including measures of endothelial dysfunction and of low-grade inflammation, are as closely related to insulin resistance as are the classic components of the syndrome. Because it is difficult to envisage how these traits might develop as a consequence of insulin resistance, such observations indicate the need for a new paradigm to explain the mechanisms of association better. It has been proposed that a state of low-grade inflammation, consequent upon the production of adipocytokines, particularly from truncal fat, explains the observed relationships between insulin resistance and endothelial dysfunction better than does a model revolving around insulin resistance. Furthermore, the inflammatory cytokines generated from adipose tissue may influence vessel endothelial function without elevations in circulating concentrations. This review alludes to several problems inherent in the epidemiological method in understanding disease
\end{abstract}

\author{
J. S. Yudkin $(\bowtie)$ \\ Department of Medicine, University College London, \\ Archway Campus, \\ Holborn Union Building, Highgate Hill, \\ London N19 5LW, UK \\ e-mail: j.yudkin@ucl.ac.uk \\ Present address: \\ J. S. Yudkin \\ 28 Huddleston Road, \\ London N7 0AG, UK
}

mechanisms. These include crude biological measures, the use of venous systemic fasting samples, imprecision of assays, naive physiological models, simplistic statistical approaches and, without clinical trials, an inability to test causation. Integrated systems biology needs more complex approaches to investigate disease mechanisms, involving cell, organ, whole organism and population studies.

Keywords Adipocytokines · Endothelium · Inflammation · Insulin resistance $\cdot$ Metabolic syndrome
Abbreviations
CRP C-reactive protein
HOMA homeostasis model assessment
NO nitric oxide
PAI-1 plasminogen activator inhibitor-1
UKPDS United Kingdom Prospective Diabetes Study
VLDL very-low-density lipoprotein

\section{Introduction}

In his 1988 Banting lecture, Reaven described the clustering of cardiovascular risk factors that he termed syndrome X [1]. These comprised resistance to insulin-stimulated glucose uptake, hyperglycaemia, hyperinsulinaemia, increased plasma concentration of very-low-density lipoprotein (VLDL)triacylglycerol, a low concentration of HDL-cholesterol and high blood pressure. Many other terms have been used to describe such a cluster [2-4], the most common being the metabolic syndrome. This syndrome has been defined in different ways by different bodies [5-7], but all include (central) obesity, dyslipidaemia, hypertension and glucose intolerance. Although these definitions do not attempt to ascribe any aetiological factor to the cluster, and only one 
definition, that of the $\mathrm{WHO}$, includes insulin resistance as one of the components [6], there still remains a widely held belief that insulin resistance plays an important role. As examples, the National Cholesterol Education ProgramAdult Treatment Panel III states that the 'syndrome is closely linked to a generalized metabolic disorder called insulin resistance' [5], and the International Diabetes Federation Consensus Statement [7] notes that insulin resistance is widely believed to be a central feature of the metabolic syndrome, even though the mechanistic link between insulin resistance and most of the components of the metabolic syndrome is not fully understood'. Thus, the core concept of syndrome $\mathrm{X}$, and by extrapolation the metabolic syndrome, has been the centrality of insulin resistance and/or hyperinsulinaemia, in part determined by obesity, but leading, through various mechanisms, to the clustering of lipid abnormalities, elevated blood pressure and glucose intolerance [1].

There has recently been substantial debate about the value of defining a metabolic syndrome, and even about its very existence, but one focus of the debate has been the issue of its pathophysiology [8-10]. The joint statement by the American Diabetes Association and the European Association for the Study of Diabetes noted that most investigators use the phrase 'insulin resistance' to describe the hallmark of the syndrome, but that there was substantial inconsistency in such associations, in part because of measurement problems [8]. Gale commented that 'insulin resistance, important though it may be, provides an insecure foundation for the metabolic syndrome, to the extent that it is no longer considered a useful (or at least measurable) criterion' [10]. He continued, 'A number of associated clinical features congregate in individuals who are at increased risk of heart disease. They cluster together for a reason, and it is important to seek an explanation for this at a pathophysiological level.'

This article will use these critiques as a starting point to look for a reason for the clustering, and in so doing, challenge the evidence for insulin resistance being the central aetiological factor. It will outline the expansion of the syndrome to include several new variables for which, unlike the original components, explanations of pathogenesis based on insulin resistance appear tenuous. It will suggest that one of the major problems in many of the studies of the metabolic syndrome is the problem of confounding, as a consequence of taking inadequate account of body fat mass. It will go on to propose a more feasible model for the observed associations, one in which adipose tissue-derived molecules generate a state of low-grade inflammation, with consequent changes in metabolic and haemodynamic physiology.

This critique of the dominant paradigm for the metabolic syndrome will also have a subsidiary theme. Most of the literature on the metabolic syndrome is based on findings from epidemiological studies, which have, by their very nature, many limitations in pursuing ideas of causation. The article will outline some of these epidemiological pitfalls, including that of confounding, and will suggest that such approaches may have been responsible in part for the naive physiological models that have been proposed. It will suggest that additional methods are necessary to understand aetiology, and, in turn, to help define treatment strategies. To begin this deconstruction, it is necessary to consider what makes a syndrome.

\section{Clustering of continuous variables}

The term 'syndrome' is defined as the concurrence of symptoms and signs in a disease, the word deriving from

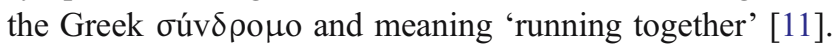
In Cushing's syndrome, where such signs include striae, moon face and buffalo hump, or in AIDS, where the presence of immune deficiency is defined on the basis of particular opportunistic infections, the component parts are categorical variables that are either present or absent. With the metabolic syndrome, however, the variables used in its definition are continuous, quantitative ones. Even though these can be turned into categorical variables, such as hypertension or impaired fasting glucose, by ascribing arbitrary cut-off points, the definition of clustering of the quantitative traits must depend on their closeness of the association, again a continuous quantitative attribute for which shades of proximity can exist. These issues, of how close an association needs to be, and also of how close is the true association between variables, are problematic, as will now be outlined.

\section{Problems in defining clustering of continuous variables}

- Strength of even weak associations may achieve significance in large studies

- Poor reproducibility of single measures (biological or assay) will affect correlations

- Hierarchy of relationships may alter when reproducibility is taken into account

- Interrogative statistical methods may show that more than one cluster exists

- Inadequate account of confounding variables may leave significant associations

In his original description, Reaven implicated insulin resistance in syndrome $\mathrm{X}$ by showing statistically significant correlation coefficients between the dependent variables and the concentrations of insulin [12]. Table 1 shows similar correlation coefficients between these variables in 1034 healthy men and women aged 40-75 years investi- 
Table 1 Correlations of metabolic syndrome variables in the Goodinge study ([13, 14], $n=1034)$

\begin{tabular}{|c|c|c|c|c|c|c|}
\hline & $\begin{array}{l}\text { Fasting insulin } \\
\text { concentration }\end{array}$ & $\begin{array}{l}2 \mathrm{~h} \text { insulin } \\
\text { concentration }\end{array}$ & $\begin{array}{l}\text { Systolic blood } \\
\text { pressure }\end{array}$ & $\begin{array}{l}\text { Diastolic blood } \\
\text { pressure }\end{array}$ & Triacylglycerol & $\begin{array}{l}\text { HDL- } \\
\text { cholesterol }\end{array}$ \\
\hline $\begin{array}{c}\text { Fasting insulin } \\
\text { concentration }\end{array}$ & - & $0.51 * * *$ & $0.21 * * *$ & $0.17 * * *$ & $0.30 * * *$ & $-0.22 * *$ \\
\hline $\begin{array}{l}2 \mathrm{~h} \text { insulin } \\
\text { concentration }\end{array}$ & & - & $0.21 * * *$ & $0.18^{* * *}$ & $0.30 * * *$ & $-0.18 * * *$ \\
\hline $\begin{array}{l}\text { Systolic blood } \\
\text { pressure }\end{array}$ & & & - & $0.73 * * *$ & $0.24 * * *$ & $-0.04^{\mathrm{a}}$ \\
\hline $\begin{array}{l}\text { Diastolic blood } \\
\text { pressure }\end{array}$ & & & & - & $0.20 * * *$ & $-0.07^{*}$ \\
\hline Triacylglycerol & & & & & - & $-0.48 * * *$ \\
\hline
\end{tabular}

$* p<0.05$

$* * p<0.01$

$* * * p<0.001$

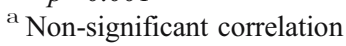

gated in the Goodinge study $[13,14]$. It is clear that there are significant correlations between all variables and both fasting and $2 \mathrm{~h}$ insulin concentrations. But when a study comprises more than 1,000 participants, significant correlations exist even with correlation coefficients as low as 0.07 , when less than $0.5 \%$ of the variance of the dependent measure is 'explained' by that of insulin concentrations.

One issue that is relevant to the strength of a relationship between two variables is that of reproducibility. In most epidemiological studies, variables are measured on a single occasion, although for some measures, such as blood pressure and anthropometry, a mean of two or three observations may be used. But when a measure is made on repeated occasions, there is substantial variability in the observed results, reproducibility decreasing with increasing interval. While part of the explanation for this lies in biological variability, there are also contributions from the method itself, with laboratories recognising variability within- and between-assays, and measures such as waist circumference, blood pressure or skinfold thickness similarly showing intra- and inter-observer variability. We have studied a series of measures in 107 healthy adults on two occasions separated by 3.5 years (J. S. Yudkin, unpublished data; $[15,16])$ and correlated values at follow-up with those at baseline. These correlation coefficients vary from $r=0.90$ for BMI to $r=0.46$ for fasting triacylglycerol and $r=0.32$ for fasting insulin concentrations. This repeat measurement variability will influence the correlation between any two measures in a population study, and it is possible, in correlation analyses, to make corrections for the imprecision resulting from measurement variability $[17,18]$. This approach is shown in Fig. 1. Figure 1a shows the correlation coefficients in the Goodinge study between fasting insulin concentrations and measures of obesity, blood pressure and lipids, as well as a number of other variables that have been proposed to associate with insulin
resistance-NEFAs [19], albumin excretion rate [15], plasminogen activator inhibitor-1 (PAI-1, an inhibitor of fibrinolysis) [20] and markers of low-grade inflammation [16]. The strengths of the associations are shown by the proximity of the variable to the centre. In Fig. 1b, the associations are shown again, but this time after correcting the correlations for variability, calculated as a coefficient of variation for repeated measures over 3.5 years. All the relationships become stronger, in part because the variability of the insulin measurement is nullified, but more notable is the change in the ranking order of variables after such a correction. Thus the corrected correlation coefficients of between 0.25 and 0.30 are seen not only for blood pressure and HDL-cholesterol, but also for C-reactive protein (CRP) and fibrinogen; albumin excretion rate shows a corrected correlation coefficient with hyperinsulinaemia of 0.40 ; and PAI-1 activity shares with triacylglycerol concentration a corrected coefficient of about 0.7 . It seems, then, that the variables that comprise the metabolic syndrome need to be expanded to include PAI-1, markers of low-grade inflammation and microalbuminuria, this last perhaps representing a manifestation of endothelial damage or dysfunction [21, 22]. The issue of biological plausibility of a cause-andconsequence relationship with insulin resistance [23] will be considered below.

Besides issues of defining what is meant by association, there are challenges to the concept of a single cluster. More interrogative approaches to exploring clustering of metabolic syndrome variables are now widely employed, and in particular the technique of factor analysis. Most such studies seem to suggest the existence of three or four separate clusters, generally relating to insulin, to lipids and to blood pressure, with obesity sometimes linked to insulin or lipids, or sometimes forming a separate factor [24-26]. Quite clearly, from these analyses, the concept of a single syndrome revolving around, and caused by, insulin resis- 
Fig. 1 Correlations between components of the 'expanded syndrome $\mathrm{X}$ ' and insulin concentrations in the Goodinge study $[13,14]$. a Shows raw correlation coefficients and b shows correlation coefficients adjusted for biological and measurement variability. The lengths of the spokes are related to the strengths of the correlations, such that the most closely correlated variables lie closer to the centre. Numbers of measurements for the variables ranged from 107 to 1,034 . For further details, see text. $D B P$ Diastolic blood pressure, $S B P$ systolic blood pressure, $T G$ triacylglycerol

a

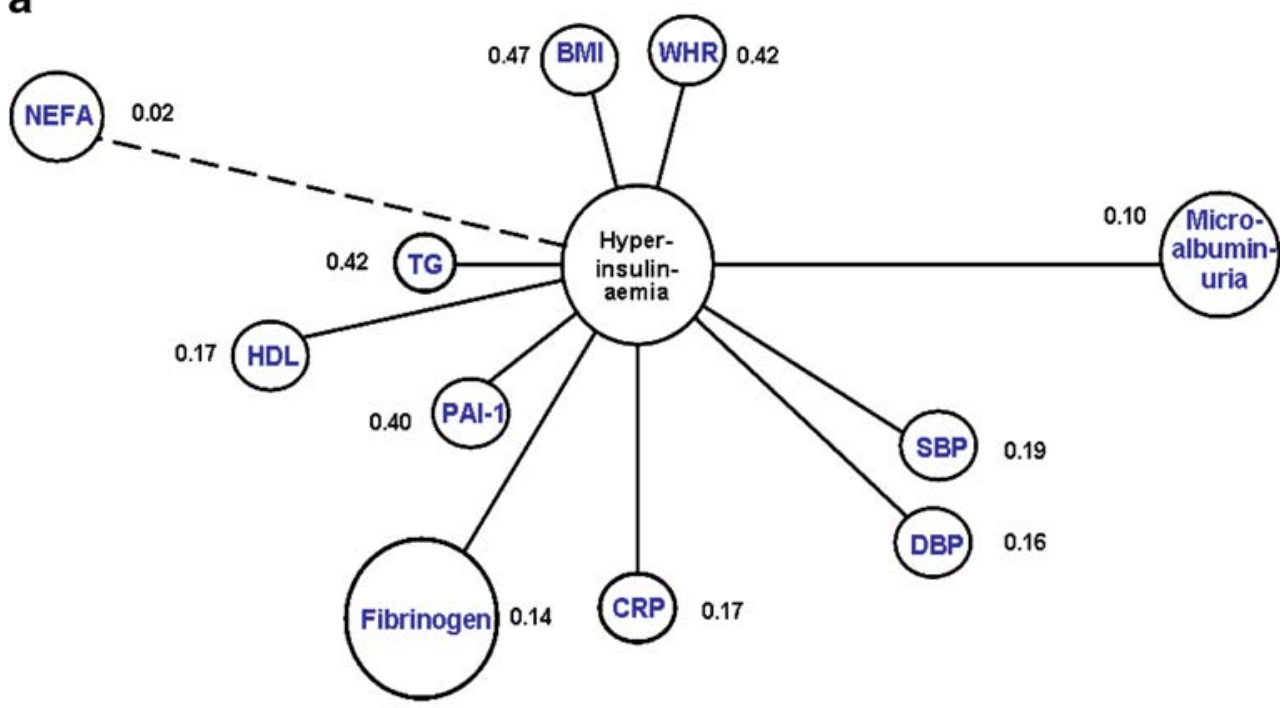

b

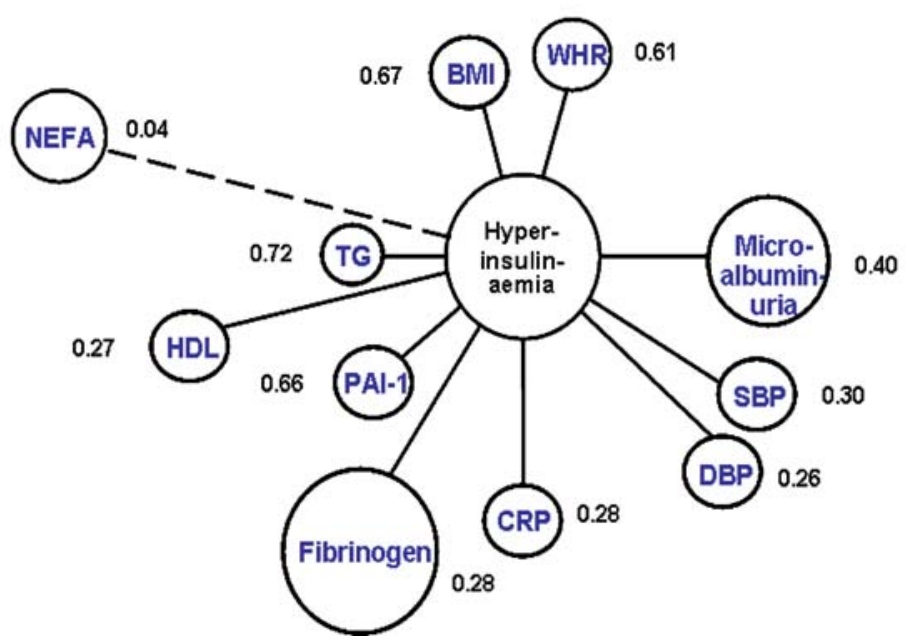

tance and/or hyperinsulinaemia is difficult to sustain. And as the metabolic syndrome has expanded to include new members, so has the concept of this single central determinant become even more tenuous.

\section{New members of the metabolic syndrome and their pathophysiology}

The next question that will be tackled is that of plausibility of cause-and-consequence relationships with insulin resistance. In his 1988 paper, Reaven proposed convincing mechanisms as to how insulin resistance, in adipose tissue and in the liver, might lead not only to glucose intolerance, but also to the typical metabolic syndrome dyslipidaemia [1]. The mechanisms suggested for the existence of hypertension as part of the syndrome, however, depended more on the hyperinsulinaemia necessary, in an insulin-resistant individual, to maintain euglycaemia [1]. The gold standard for measurement of insulin resistance is the euglycaemic-hyperinsulinaemic clamp [27], a measure of peripheral glucose uptake under situations of elevated insulin concentrations, a method which is difficult to apply

\section{Hyperinsulinaemia and the metabolic syndrome - issues of plausibility}

- Most epidemiological studies of the metabolic syndrome estimate insulin resistance from fasting insulin concentrations (or HOMA-model derived insulin sensitivity)

- Such a measure correlates weakly with clamp insulin sensitivity measures

- Cross-reaction with proinsulin is not a problem with new assays, but proinsulin correlations are generally stronger than those for insulin

- All these considerations raise questions around the plausibility of insulin resistance as a central mechanism 
in larger populations studies. For this reason, most such studies use a measure of fasting insulin as a surrogate for insulin resistance, or derive an estimate of insulin resistance using the homeostasis model assessment (HOMA) model [28], which, in non-diabetic populations correlates extremely closely with fasting insulin concentrations, with correlation coefficients of about $r=0.98-0.99$. Other estimates of insulin resistance that are based on a combination of fasting and post-load insulin concentrations can also be used [29, 30]. The relationship between insulin concentrations and clamp measures of insulin resistance is only moderate, with a correlation coefficient of $r=-0.34$ between $\mathrm{M}$ value corrected for lean body mass and fasting insulin concentrations in 1,519 subjects in the European Group on Insulin Resistance Database (E. Ferrannini, unpublished data; [31]). This observation has implications for considerations of pathophysiology, for if a variable is regulated by insulin resistance but the measure being employed to assess it is such a poor indicator of insulin resistance, then one might have to postulate other explanations for the associations.

Some years ago, it was shown that the standard insulin immunoassays cross-reacted with the biologically less active insulin precursor molecules proinsulin and its split products [32]. This observation, and emerging assays that permitted specific measures of both insulin and these proinsulin-like molecules, led to studies that found that the correlations of concentrations of these molecules were stronger than those for insulin itself [33], despite their having little biological activity. So once again, epidemiological correlations which were demonstrated were difficult to explain physiologically.

The expansion of the metabolic syndrome to incorporate a series of new candidates has already been introduced.
Thus elevated concentrations or activity of PAI, an inhibitor of fibrinolysis, are regularly described in obese or insulinresistant subjects [20], as are increased urinary excretion of albumin [15] and indices of low-grade inflammation, such as fibrinogen and C-reactive protein (CRP) $[14,16]$. In 1965 Sir Austin Bradford Hill analysed the aspects of epidemiological associations that should be considered before deciding that the most likely interpretation is that of causation - one of which is 'plausibility' [23]. And, while recognising that what may, or may not, appear plausible is dependent on prior beliefs [34], in this instance it requires the need for a biological understanding, not only as to why concentrations of proinsulin relate to the metabolic syndrome variables more closely than do those of insulin, but also of how insulin resistance or hyperinsulinaemia might produce inflammation (CRP, fibrinogen) and endothelial dysfunction (microalbuminuria). The issue of confounding is relevant to this argument, as it will be suggested that unconsidered confounders may profoundly influence the relationships observed between variables, either to strengthen or to weaken the apparent correlation.

\section{Associations may be the consequence of unconsidered confounders}

Many of the variables that have been related to insulin concentrations or resistance, both original and new, are strongly associated with obesity. As acknowledged by Reaven [35], obesity is a cause of insulin resistance, but is also strongly associated with hypertension, dyslipidaemia and glucose intolerance. Table 2 shows the correlations of BMI with fasting and $2 \mathrm{~h}$ insulin concentrations and with the

Table 2 Correlations of metabolic syndrome variables in the Goodinge study [13, 14] without and with correction for BMI $(n=1034)$

\begin{tabular}{|c|c|c|c|c|c|c|}
\hline & $\begin{array}{l}\text { Fasting insulin } \\
\text { concentration }\end{array}$ & $\begin{array}{l}2 \mathrm{~h} \text { insulin } \\
\text { concentration }\end{array}$ & $\begin{array}{l}\text { Systolic blood } \\
\text { pressure }\end{array}$ & $\begin{array}{l}\text { Diastolic blood } \\
\text { pressure }\end{array}$ & Triacylglycerol & HDL-cholesterol \\
\hline BMI & $0.37 * * *$ & $0.31 * * *$ & $0.29 * * *$ & $0.27 * * *$ & $0.35 * * *$ & $-0.30 * * *$ \\
\hline $\begin{array}{l}\text { Fasting insulin } \\
\text { concentration }\end{array}$ & - & $0.51 * * * / 0.46 * * *$ & $0.21^{* * *} / 0.11^{* * *}$ & $0.17 * * * / 0.08 *$ & $0.30 * * * / 0.19 * * *$ & $-0.22 * * * /-0.12 * * *$ \\
\hline $\begin{array}{l}2 \mathrm{~h} \text { insulin } \\
\text { concentration }\end{array}$ & & - & $0.21 * * * / 0.13 * *$ & $0.18^{* * * / 0.11 * *}$ & $0.30 * * * / 0.22 * * *$ & $-0.18 * * * /-0.09 * *$ \\
\hline $\begin{array}{l}\text { Systolic blood } \\
\text { pressure }\end{array}$ & & & - & $0.73 * * * / 0.71 * * *$ & $0.24 * * * / 0.15 * * *$ & $-0.04^{\mathrm{a}} /-0.05^{\mathrm{a}}$ \\
\hline $\begin{array}{l}\text { Diastolic blood } \\
\text { pressure }\end{array}$ & & & & - & $0.20 * * * / 0.12 * * *$ & $-0.07 * / 0.01^{\mathrm{a}}$ \\
\hline Triacylglycerol & & & & & - & $-0.48 * * * /-0.42 * * *$ \\
\hline
\end{tabular}


metabolic syndrome variables shown in Table 1, demonstrating the effect of controlling these univariate correlations for BMI. The strength of all relationships is reduced by between one-third and one-half, an effect that might be even greater with a more precise measure of total body fat [36]. But not all fat is alike. Waist circumference, or waist-to-hip ratio, provides a much more powerful prediction of incident cardiovascular disease than does BMI [37], and central fat also contributes strongly to the risk of incident diabetes [38]. Similarly, truncal fat as measured by waist circumference or subscapular skinfold thickness, or visceral fat by computed tomography or magnetic resonance imaging scan, are powerfully related to measures of insulin resistance [39, 40]. Indeed, all three of the widely accepted definitions of the metabolic syndrome now include a measure of central obesity [5-7]. The issue here, then, is whether accurate measures of body fat mass and its distribution might underlie the clustering of risk factors, and if so, whether such an association is the consequence of adipose-induced insulin resistance or through the mediation of some other signal.

As well as unconsidered confounders being responsible for associations attributed to insulin resistance, there is also the possibility that they may help explain relationships which seem biologically implausible. As has been outlined,

\section{Insulin resistance, the metabolic syndrome and} endothelial dysfunction-cause, consequence or common antecedent?

- Insulin resistance/hyper/insulinaemia causes hypertension, dyslipidaemia, glucose intolerance and endothelial dysfunction (for example [1])

- Endothelial dysfunction causes hypertension, glucose intolerance and insulin resistance (for example [45])

- Both endothelial dysfunction and the metabolic syndrome, including insulin resistance, are the consequence of a common antecedent, such as low-grade inflammation [16]

there is an issue of plausibility when the central mechanism proposed to hold together the growing range of metabolic syndrome variables is insulin resistance. In particular, the coexistence of microalbuminuria with insulin resistance in diabetic [41] and non-diabetic subjects [15], and the link of insulin resistance with other measures of endothelial dysfunction [42-44], are difficult to conceptualise as a cause-and-consequence relationship. Although it is possible that there is a reverse aetiology, whereby insulin resistance is a consequence of endothelial dysfunction [45], for example through impairment of insulin-dependent vasodilatation [46, 47], of trans-endothelial insulin transport [48] or of insulin-induced recruitment of nutritive capillary networks [47], another explanation is also possible. This is that both insulin resistance and endothelial dysfunction are consequences of a common aetiological mechanism.

Exploring the relationships of metabolic syndrome variables in a population of healthy adults, we reported good correlations with a factor score of low-grade inflammation, derived from circulating concentrations of the cytokines TNF- $\alpha$ and IL-6, and the acute-phase markers CRP and fibrinogen [16]. Indeed, this correlation between an 'insulin resistance' $z$-score and an 'acute-phase' $z$-score of $r=0.59$, suggests that even using these crude approaches, some $35 \%$ of the variance of the measures comprising the metabolic syndrome could be 'explained' by a state of lowgrade inflammation. Furthermore, this 'acute-phase' marker score also correlated well with markers of endothelial activation, such that there was no residual statistical link between endothelial dysfunction and insulin resistance once the inflammatory markers were included in the equation [16]. These findings raise the possibility that the association between insulin resistance and the components of the metabolic syndrome is the consequence of their being common outcomes of a state of low-grade inflammation.

A similar conclusion emerges from studies using factor analysis. As outlined earlier, this approach has been used to characterise patterns of clustering among the syndrome $\mathrm{X}$ variables, and most such studies have employed only the classic components of the syndrome, plus obesity. If, however, one includes inflammatory markers in such a factor analysis, as we have done in 469 men with myocardial infarction and in 575 controls [49], then the 'metabolic syndrome' factor is closely related to a lowgrade inflammation factor in both subject groups. Another study, in 236 native Canadian children [50], showed that without inclusion of acute-phase markers, there were relationships of insulin concentrations with dyslipidaemia and obesity, but not with blood pressure. If, however, measures of three acute-phase markers (CRP, IL-6 and serum amyloid A) were included in the model, the relationship between insulin concentrations and dyslipidaemia also disappeared.

The next issue, then, is how to explain a low-grade inflammatory state in healthy subjects. Our own observations failed to find major relationships of these acute-phase markers and cytokines with titres of antibodies against Helicobacter pylori, Chlamydia and cytomegalovirus [16]. There were, however, strong and consistent relationships with anthropometric measures of obesity and central fat distribution, such that about $20 \%$ of the variance of the acute phase $z$-score could be explained, statistically, on the basis of adiposity [16]. Adipose tissue generates proinflammatory cytokines, whether from adipocytes or from infiltrating macrophages, an observation that has become a 


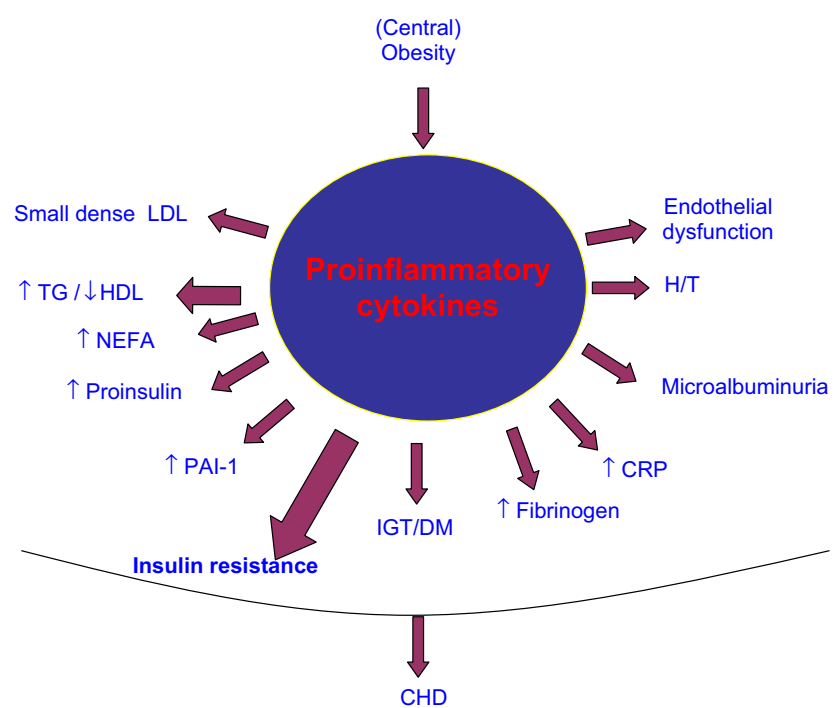

Fig. 2 An inflammation-centred paradigm for 'expanded syndrome X'. H/T Hypertension, $T G$ triacylglycerol

major research theme in recent years. The pioneering work of Hotamisligil and Speigelman [51], showing the effect of TNF- $\alpha$ on inhibition of the insulin signalling pathway, has led to the exploration and characterisation of several other adipocytokines with similar metabolic functions [52]. And the fact that these cytokines inhibit the effect of insulin on endothelial cells $[53,54]$ may additionally contribute to insulin resistance by limiting nutrient-induced increases in nutritive capillary flow to muscle, as well as muscle glucose uptake.

So a new, and perhaps more likely, paradigm for the metabolic syndrome seems to be that of adipose tissuegenerated molecules initiating a state of low-grade inflammation, with the known actions of these proinflammatory cytokines [16] resulting in the combined metabolic, haemodynamic and vascular consequences of this state. And in this model, insulin resistance becomes merely another consequence of this low-grade inflammatory state. The paradigm is illustrated in Fig. 2. But the proposed model raises a new question: How does excess fat mass signal to the organs involved in the pathophysiology of the metabolic syndromethe liver, skeletal muscle and blood vessels?

\section{The metabolic syndrome-a consequence of endocrine signals?}

In large population studies, blood samples are generally taken from a vein, usually in the fasting state. This means that non-endocrine signals, such as those limited to a portal or an arterial circulation, or signals in the postprandial state, remain undocumented.
As outlined above, the best characterised of the adipocytokines, in terms of effects on insulin action, is TNF- $\alpha$, which has powerful effects on inhibiting insulin signalling in the adipocyte, liver and skeletal muscle, as well as in the whole organism [51, 55]. Moreover, TNF- $\alpha$ also inhibits endothelial nitric oxide (NO)-dependent vasodilatation [56] and activates production of adhesion molecules by endothelial cells [57]. But TNF- $\alpha$ does not have the characteristics of a circulating endocrine signal. First, our group has found no net adipose tissue release of the cytokine, as measured by arterio-venous difference across a subcutaneous adipose tissue bed [58]. Second, other than in states of sepsis, circulating concentrations of TNF- $\alpha$ are below those likely to saturate soluble binding proteins [51]. Is it possible, then, that TNF- $\alpha$ is acting in a non-endocrine fashion?

A substantial component of adipose tissue TNF- $\alpha$ production arises from infiltrating macrophages [59], and this infiltration may represent an important paracrine mechanism whereby increasing fat mass induces adipocyte insulin resistance. Increasing fat mass and adipose tissue macrophage infiltration are also associated with increased liver fat content [60], a state in which liver production of TNF- $\alpha$ is increased and hepatic insulin action impaired [61], again through local and not systemic effects of the cytokine. Ectopic fat within skeletal muscle fibres is also associated with insulin resistance [62]. We have recently suggested that, in a similar fashion, ectopic fat around blood vessels, through increased production and local action of adipocytokines, may also play an important role

\section{Normal $\square \longrightarrow$ Obesity}

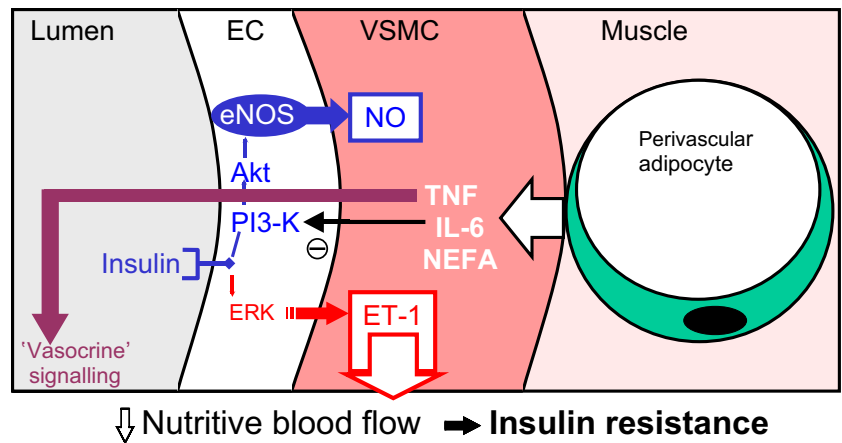

Fig. 3 Vasocrine signalling from perivascular fat. Adipocytokines secreted from perivascular adipocytes inhibit the phosphoinositol 3kinase $(P I 3-K)$ pathway of insulin signalling, leaving unopposed vasoconstrictor effects of endothelin-1 (ET-1). High concentrations of TNF- $\alpha$ access the vascular lumen, resulting in inhibition of endothelial PI3-K pathway insulin signalling in downstream vessels. Reduced insulin-mediated enhancement of muscle nutritive blood flow will contribute to insulin resistance. EC Endothelial cell, eNOS endothelial nitric oxide synthase, ERK extracellular signal-related kinase, VSMC vascular smooth muscle cell 
in skeletal muscle blood flow and insulin action, and indeed in vascular disease [63].

The endothelium is an insulin responsive organ, with insulin stimulating both vasodilatory and vasoconstrictive pathways. Insulin stimulates NO synthase production and activation through the phosphoinositol 3-kinase pathway, but also activates release of endothelin-1 through the extracellular-regulated kinase $1 / 2$ pathway. In nutritive arterioles supplying skeletal muscle, the vasodilatory pathway predominates, with physiological elevation of insulin concentrations producing rapid shunting of blood flow from non-nutritive circuits, contributing to insulin action through increasing insulin and substrate delivery to insulin-sensitive tissues [64]. Our data from Zucker fatty rats, and from rats fed a high-fat diet, show the development of a cuff of fat around the origin of muscle nutritive arterioles, associated with complete inhibition of insulinmediated vasodilatation in the downstream vessel, insulin instead producing endothelin-1-mediated vasoconstriction of the arteriole [63]. The fact that the vasoactive effect is downstream from the fat pad has led to the proposal of a 'vasocrine' hypothesis [63] (Fig. 3) - that in obesity, signalling molecules such as TNF- $\alpha$, generated by periarteriolar fat, influence vasoresponsiveness to insulin in the downstream vascular bed fed by the nutritive arteriole, so contributing to the insulin insensitivity. However, because this signal becomes diluted in the general venous, or systemic, circulation it is not sufficient in amount to influence systemic vascular function.

We have also proposed a homology between periarteriolar fat, having a vasoregulatory function in obesity, with other depots of perivascular fat around arteries, in the mediastinum, neck and trunk [63]. Mazurek et al. [65] have shown marked inflammatory cell infiltration in epicardial fat, these cells converting the adipose tissue to a phenotype with high expression and secretion of chemokines and adipocytokines, with probably outside-to-inside signalling effects on arterial plaque inflammation. We have postulated that the relationship between central obesity and coronary heart disease may relate to the homology of visceral and truncal fat on the one hand with periarterial (atherogenic) and periarteriolar fat (insulin resistance) on the other [63].

\section{Demonstrating causation-the need for experiment}

The demonstration of correlation is clearly not proof of causation. One of the considerations listed by Bradford Hill [23] as strengthening the presumption of a cause-andconsequence relationship was 'experiment' - if a putative causal variable is altered and the supposed dependent variable changes in consequence, then the hypothesis of causation is supported, or at least not refuted [66, 67]. So how good is the evidence on insulin resistance and its relationships with the metabolic syndrome? Is there evidence to implicate low-grade inflammation as the cause of obesity-related insulin resistance? And can insulin resistance or inflammation be implicated in the putative downstream consequence of the metabolic syndrome, cardiovascular disease? A variety of animal studies, in which inflammatory pathways are manipulated in adipose tissue or in macrophages, strongly support the role of inflammation as a cause of insulin resistance [6870]. But animal studies are not able readily to answer questions about cardiovascular disease. Human studies of organ-specific gene knockouts or upregulation present different obstacles, although the concept of 'Mendelian randomisation' has been used, particularly in cardiovascular risk, to explore the role of several putative mechanisms [71]. Human intervention studies are generally pharmacological.

Perhaps, despite everything that has gone before, the most important observation in regard to the role of insulin resistance is the result of the metformin component of the UK Prospective Diabetes Study (UKPDS) [72]. Metformin increases insulin sensitivity, and has effects on lipids and blood pressure [73]. In the UKPDS, overweight participants with type 2 diabetes were randomised to a variety of glucose-lowering agents, including metformin. Of all the interventions, it was only metformin treatment that was associated with a reduction in the incidence of myocardial infarction, by $39 \%$ [72]. Perhaps, after all, insulin resistance does play a role in macrovascular disease in diabetic subjects. But what about the 'insulin sensitisers'- the thiazolidinediones? The first published outcome study using such drugs was the PROactive study [74], which had the headline result of a significant reduction in macrovascular events during treatment with pioglitazone. This study has been heavily criticised on the basis of its failure, in the statistical analysis for this secondary endpoint, to allow for multiple comparisons $[75,76]$, the primary endpoint being reduced by an insignificant $10 \%$. In any event, in the context of the Bradford Hill criteria [23], the thiazolidinediones might be considered a less valid test of the insulin resistance hypothesis than is metformin, because of the multiple additional effects of this class of drugs on inflammatory and other signalling pathways and on risk factors [77], and not solely on improving insulin signalling. As to the effects of targeting inflammation, there are ongoing studies of salsalate, a derivative of salicylic acid, on incidence of cardiovascular disease in diabetic patients, encouraged by observations that the drug, when used in antiinflammatory doses, improves insulin sensitivity [78]. 


\section{Conclusion}

This review has attempted to suggest a novel paradigm for the aetiology of the metabolic syndrome and its link to cardiovascular disease. It has also pointed out a number of pitfalls of the epidemiological approach, which, it is suggested, is valuable for generating a hypothesis but is not able rigorously to test it. These pitfalls of epidemiology

\section{The pitfalls of epidemiological approaches to the metabolic} syndrome

- Crude biological measures may represent a variety of regulated pathways (for example, blood pressure)

- Assay measures may represent active and inactive molecules (for example, insulin, adiponectin)

- Systemic venous fasting samples are unable to reflect

- postprandial or diurnal systemic signals

- regional (for example, arterial, portal or vasocrine) signals

- Measures of association used to impute causation

- arbitrariness of cut-offs for significance

- dependence on sample size

- effect of biological and assay variability

- Single cluster may in fact represent multiple overlapping clusters

- Unconsidered confounders may weaken observed associations

- Unconsidered confounders may be responsible for observed associations

- Associations may represent cause, consequence, or common antecedent

- Testing of causality requires 'experimentation'

are listed in the text box. They include: the crude biological measures that are generally able to reflect only a single component of a highly regulated biological variable; imprecision of assays and naive physiological models; the use of venous systemic fasting samples; simplistic statistical approaches, the significance of the results depending on a variety of factors including sample size and biological variability of the measure; the problem of confounders, whose inclusion and measurement will depend on dominant paradigms; and, without clinical trials, an inability to test causation. In reality an organism is a much more complex series of integrated systems that need more complex approaches to investigate disease mechanisms, involving cell, organ, whole organism and population investigations. As to the mechanisms involved in the clustering of cardiovascular risk factors, it appears that several of these do cluster together in obese individuals, who demonstrate a state of low-grade inflammation, endothelial dysfunction and insulin resistance. This article has suggested that central distribution of fat, and its ectopic deposition in liver, muscle and around blood vessels, may be the unifying mechanism linking central obesity, insulin resistance and macrovascular disease. But like any scientific conjecture, this is now merely available for refutation [66].

Acknowledgements I would like to thank C. D. A. Stehouwer for valuable discussions and insights both during the collaborations that have generated some of these data and during the evolution of the content of the analyses.

Duality of interest The author has no duality of interest.

\section{References}

1. Reaven GM (1988) Role of insulin resistance in human disease. Banting lecture 1988. Diabetes 37:1595-1607

2. Ferrannini E, Haffner SM, Mitchell BD, Stern MP (1991) Hyperinsulinaemia: the key feature of a cardiovascular and metabolic syndrome. Diabetologia 34:416-422

3. Kaplan NM (1989) The deadly quartet. Upper-body obesity, glucose intolerance, hypertriglyceridemia, and hypertension. Arch Intern Med 149:1514-1520

4. Hjermann I (1992) The metabolic cardiovascular syndrome: syndrome X, Reaven's syndrome, insulin resistance syndrome, atherothrombogenic syndrome. J Cardiovasc Pharmacol 20(Suppl 8):S5-S10

5. Expert Panel on Detection, Evaluation, and Treatment of High Blood Cholesterol in Adults (2001) Executive summary of the third report of the National Cholesterol Education Program (NCEP) Expert Panel on Detection, Evaluation, and Treatment of High Blood Cholesterol In Adults (Adult Treatment Panel III). JAMA 285:2486-2497

6. World Health Organization (1999) Definition, diagnosis and classification of diabetes mellitus: report of a WHO consultation. Part 1: diagnosis and classification of diabetes mellitus, $\mathrm{WHO} /$ NCD/NCS/99.2. WHO, Geneva

7. Alberti KG, Zimmet P, Shaw J (2006) Metabolic syndrome-a new world-wide definition. A consensus statement from the International Diabetes Federation. Diabet Med 23:469-480

8. Kahn R, Buse J, Ferrannini E, Stern M (2005) The metabolic syndrome: time for a critical appraisal. Joint statement from the American Diabetes Association and the European Association for the Study of Diabetes. Diabetologia 48:1684-1699

9. Grundy SM (2006) Does the metabolic syndrome exist? Diabetes Care 29:1689-1692

10. Gale EA (2005) The myth of the metabolic syndrome. Diabetologia 48:1679-1683

11. Translatum (2006) Translatum: the Greek translation vortal. http:// www.translatum.gr/forum/index.php?action=search2. Cited 18 October 2006

12. Fuh MM, Shieh SM, Wu DA, Chen YD, Reaven GM (1987) Abnormalities of carbohydrate and lipid metabolism in patients with hypertension. Arch Intern Med 147:1035-1038 
13. Gould MM, Mohamed-Ali V, Goubet SA, Yudkin JS, Haines AP (1993) Microalbuminuria: associations with height and sex in non-diabetic subjects. BMJ 306:240-242

14. Mohamed-Ali V, Gould MM, Gillies S, Goubet S, Yudkin JS, Haines AP (1995) Association of proinsulin-like molecules with lipids and fibrinogen in non-diabetic subjects - evidence against a modulating role for insulin. Diabetologia 38:1110-1116

15. Foyle W-J, Carstensen E, Fernández M, Yudkin JS (1995) A longitudinal study of associations of microalbuminuria with the insulin resistance syndrome and sodium-lithium countertransport in non-diabetic subjects. Arterioscler Thromb Vasc Biol 15:1330-1337

16. Yudkin JS, Stehouwer CDA, Emeis JJ, Coppack SW (1999) Creactive protein in healthy subjects: associations with obesity, insulin resistance, and endothelial dysfunction: a potential role for cytokines originating from adipose tissue? Arterioscler Thromb Vasc Biol 19:972-978

17. Levy J, Morris R, Hammersley M, Turner R (1999) Discrimination, adjusted correlation, and equivalence of imprecise tests: application to glucose tolerance. Am J Physiol 276:E365-E375

18. Hermans MP, Levy JC, Morris RJ, Turner RC (1999) Comparison of insulin sensitivity tests across a range of glucose tolerance from normal to diabetes. Diabetologia 42:678-687

19. Baldeweg SE, Golay A, Natali A, Balkau B, Del Prato S, Coppack SW (2000) Insulin resistance, lipid and fatty acid concentrations in 867 healthy Europeans. European Group for the Study of Insulin Resistance (EGIR). Eur J Clin Investig 30:45-52

20. Juhan-Vague I, Thompson SG, Jespersen J (1993) Involvement of the hemostatic system in the insulin resistance syndrome. A study of 1500 patients with angina pectoris. The ECAT Angina Pectoris Study Group. Arterioscler Thromb 13(12):1865-1873

21. Stehouwer CD, Nauta JJ, Zeldenrust GC, Hackeng WH, Donker AJ, den Ottolander GJ (1992) Urinary albumin excretion, cardiovascular disease, and endothelial dysfunction in noninsulin-dependent diabetes mellitus. Lancet 340:319-323

22. Stehouwer CDA, Yudkin JS, Fioretto P, Nosadini R (1998) How heterogeneous is microalbuminuria in diabetes mellitus? The case for "benign" and "malignant" microalbuminuria. Nephrol Dial Transplant 13:2751-2754

23. Bradford Hill A (1965) The environment and disease: association or causation. Proc R Soc Med 58:295-300

24. Meigs JB, D'Agostino RB Sr, Wilson PW, Cupples LA, Nathan DM, Singer DE (1997) Risk variable clustering in the insulin resistance syndrome. The Framingham Offspring Study. Diabetes 46: $1594-1600$

25. Shen BJ, Todaro JF, Niaura R et al (2003) Are metabolic risk factors one unified syndrome? Modeling the structure of the metabolic syndrome X. Am J Epidemiol. 157:701-711

26. Meigs JB (2000) Invited commentary: insulin resistance syndrome? Syndrome X? Multiple metabolic syndrome? A syndrome at all? Factor analysis reveals patterns in the fabric of correlated metabolic risk factors. Am J Epidemiol 152:908-911

27. Insel PA, Liljenquist JE, Tobin JD et al (1975) Insulin control of glucose metabolism in man: a new kinetic analysis. J Clin Invest 55:1057-1066

28. Matthews DR, Hosker JP, Rudenski AS, Naylor BA, Treacher DF, Turner RC (1985) Homeostasis model assessment: insulin resistance and beta-cell function from fasting plasma glucose and insulin concentrations in man. Diabetologia 28:412-419

29. Katz A, Nambi SS, Mather K et al (2000) Quantitative insulin sensitivity check index: a simple, accurate method for assessing insulin sensitivity in humans. J Clin Endocrinol Metab 85:2402-2410

30. Matsuda M, DeFronzo RA (1999) Insulin sensitivity indices obtained from oral glucose tolerance testing: comparison with the euglycemic insulin clamp. Diabetes Care 22:1462-1470
31. Ferrannini E, Balkau B (2002) Insulin: in search of a syndrome. Diabet Med 19:724-729

32. Temple RC, Clark PM, Nagi DK, Schneider AE, Yudkin JS, Hales CN (1990) Radioimmunoassay may overestimate insulin in noninsulin-dependent diabetics. Clin Endocrinol (Oxf) 32:689-693

33. Nagi DK, Hendra TJ, Ryle AJ et al (1990) The relationship of concentrations of insulin, intact proinsulin and 32-33 split proinsulin with cardiovascular risk factors in type 2 (non-insulin dependent) diabetic subjects. Diabetologia 33:532-537

34. Rothman KJ, Greenland S (2005) Causation and causal inference in epidemiology. Am J Public Health 95(Suppl 1):S144-S150

35. Reaven G (2005) Insulin resistance, type 2 diabetes mellitus, and cardiovascular disease: the end of the beginning. Circulation 112:3030-3032

36. Yajnik CS, Yudkin JS (2004) The Y-Y paradox. Clinical picture. Lancet 363:163

37. Yusuf S, Hawken S, Ounpuu S et al (2005) Interheart Study Investigators. Obesity and the risk of myocardial infarction in 27,000 participants from 52 countries: a case-control study. Lancet 366:1640-1649

38. Carey VJ, Walters EE, Colditz GA et al (1997) Body fat distribution and risk of non-insulin-dependent diabetes mellitus in women. The Nurses' Health Study. Am J Epidemiol 145:614-619

39. Misra A, Garg A, Abate N, Peshock RM, Stray-Gundersen J, Grundy SM (1997) Relationship of anterior and posterior subcutaneous abdominal fat to insulin sensitivity in nondiabetic men. Obes Res 5:93-99

40. Gastaldelli A, Miyazaki Y, Pettiti M et al (2002) Metabolic effects of visceral fat accumulation in type 2 diabetes. J Clin Endocrinol Metab 87:5098-5103

41. Nosadini R, Solini A, Velussi M et al (1994) Impaired insulininduced glucose uptake by extrahepatic tissue is hallmark of NIDDM patients who have or will develop hypertension and microalbuminuria. Diabetes 43:491-499

42. Steinberg HO, Chaker H, Leaming R, Johnson A, Brechtel G, Baron AD (1996) Obesity/insulin resistance is associated with endothelial dysfunction. Implications for the syndrome of insulin resistance. J Clin Invest 97:2601-2610

43. Weyer C, Yudkin JS, Stehouwer CD, Schalkwijk CG, Pratley RE, Tataranni PA (2002) Humoral markers of inflammation and endothelial dysfunction in relation to adiposity and in vivo insulin action in Pima Indians. Atherosclerosis 161:233-242

44. Cleland SJ, Petrie JR, Small M, Elliott HL, Connell JM (2000) Insulin action is associated with endothelial function in hypertension and type 2 diabetes. Hypertension 35(1 Pt 2):507-511

45. Pinkney J, Coppack SW, Yudkin JS (1997) Endothelial dysfunction: cause of the insulin resistance syndrome? Diabetes 46(Suppl 2):S9-S13

46. Baron AD, Clark MG (1997) Role of blood flow in the regulation of muscle glucose uptake. Annu Rev Nutr 17:487-499

47. Vincent MA, Clerk LH, Lindner JR et al (2004) Microvascular recruitment is an early insulin effect that regulates skeletal muscle glucose uptake in vivo. Diabetes 53:1418-1423

48. Bergman RN (1997) New concepts in extracellular signaling for insulin action: the single gateway hypothesis. Recent Prog Horm Res 52:359-385

49. Yudkin JS, Juhan-Vague I, Hawe E et al, the HIFMECH Study Group (2004) Low-grade inflammation may play a role in the etiology of the metabolic syndrome in patients with coronary heart disease: the HIFMECH study. Metabolism 53:852-857

50. Retnakaran R, Zinman B, Connelly PW, Harris SB, Hanley AJ (2006) Nontraditional cardiovascular risk factors in pediatric metabolic syndrome. J Pediatr 148:176-182

51. Hotamisligil GS, Speigelman BM (1994) Tumor necrosis factor alpha: a key component of the obesity-diabetes link. Diabetes 43:1271-1278 
52. Scherer PE (2006) Adipose tissue: from lipid storage compartment to endocrine organ. Diabetes 55:1537-1545

53. Youd JM, Rattigan S, Clark MG (2000) Acute impairment of insulin-mediated capillary recruitment and glucose uptake in rat skeletal muscle in vivo by TNF-alpha. Diabetes 49:1904-1909

54. Eringa EC, Stehouwer CD, Walburg K et al (2006) Physiological concentrations of insulin induce endothelin-dependent vasoconstriction of skeletal muscle resistance arteries in the presence of tumor necrosis factor-alpha dependence on c-Jun N-terminal kinase. Arterioscler Thromb Vasc Biol 26:274-280

55. Hotamisligil GS, Shargill NS, Speigelman BM (1993) Adipose expression of tumor necrosis factor-alpha: direct role in obesitylinked insulin resistance. Science 259:87-91

56. Mohamed F, Monge JC, Gordon A, Cernacek P, Blais D, Stewart DJ (1995) Lack of role for nitric oxide (NO) in the selective destabilization of endothelial NO synthase mRNA by tumor necrosis factor-alpha. Arterioscler Thromb Vasc Biol 15:52-57

57. Min JK, Kim YM, Kim SW et al (2005) TNF-related activationinduced cytokine enhances leucocyte adhesiveness: induction of ICAM-1 and VCAM-1 via TNF receptor-associated factor and protein kinase-C dependent NF-kappaB activation in endothelial cells. J Immunol 175:531-540

58. Mohamed-Ali V, Goodrick S, Rawesh A et al (1997) Subcutaneous adipose tissue secretes interleukin- 6 but not tumour necrosis factor in vivo. J Clin Endocrinol Metab 82:4196-4200

59. Weisberg SP, McCann D, Desai M, Rosenbaum M, Leibel RL, Ferrante AW Jr (2003) Obesity is associated with macrophage accumulation in adipose tissue. J Clin Invest 112:1796-1808

60. Cancello R, Henegar C, Viguerie N et al (2005) Reduction of macrophage infiltration and chemoattractant gene expression changes in white adipose tissue of morbidly obese subjects after surgery-induced weight loss. Diabetes 54:2277-2286

61. Cancello R, Tordjman J, Poitou C et al (2006) Increased infiltration of macrophages in omental adipose tissue is associated with marked hepatic lesions in morbid human obesity. Diabetes 55:1554-1561

62. Kelley DE (2002) Skeletal muscle triglycerides: an aspect of regional adiposity and insulin resistance. Ann N Y Acad Sci 967:135-145

63. Yudkin JS, Eringa E, Stehouwer CD. (2005) "Vasocrine" signalling from perivascular fat: a mechanism linking insulin resistance to vascular disease. Lancet 365:1817-1820

64. Eringa EC, Stehouwer CDA, van Nieuw Amerongen GP, Ouwehand L, Westerhof N, Sipkema P (2004) Vasoconstrictor effects of insulin in skeletal muscle arterioles are mediated by ERK1/2 activation in endothelium. Am J Physiol 287:H2043-H2048
65. Mazurek T, Zhang LF, Zalewski A et al (2003) Human epicardial adipose tissue is a source of inflammatory mediators. Circulation 108:2460-2466

66. Popper K (1963) Conjectures and refutations. Routledge and Kegan Paul, London

67. Stehouwer CDA (2006) Fundamentals of internal medicine. Int J Risk Saf Med 18:139-144

68. Cai D, Yuan M, Frantz DF et al (2005) Local and systemic insulin resistance resulting from hepatic activation of IKK- $\beta$ and NF- $\mathrm{kB}$. Nat Med 11:183-190

69. Arkan MC, Hevener AL, Greten FR et al (2005) IKK- $\beta$ links inflammation to obesity-induced insulin resistance. Nat Med 11:191-198

70. Weisberg SP, Hunter D, Huber R et al (2006) CCR2 modulates inflammatory and metabolic effects of high-fat feeding. $\mathrm{J}$ Clin Invest 116:115-124

71. Casas JP, Shah T, Cooper J et al (2006) Insight into the nature of the CRP-coronary event association using Mendelian randomisation. Int $\mathrm{J}$ Epidemiol 35:922-931

72. UK Prospective Diabetes Study (UKPDS) Group (1998) Effect of intensive blood-glucose control with metformin on complications in overweight patients with type 2 diabetes (UKPDS 34). Lancet 352:854-865

73. Nagi DK, Yudkin JS (1993) Effects of metformin on insulin resistance, risk factors for cardiovascular disease and plasminogen activator inhibitor in NIDDM subjects. A study of two ethnic groups. Diabetes Care 16:621-629

74. Dormandy JA, Charbonnel B, Eckland DJ et al, PROactive investigators (2005) Secondary prevention of macrovascular events in patients with type 2 diabetes in the PROactive study (PROspective pioglitAzone clinical trial in macrovascular events): a randomised controlled trial. Lancet 366:1279-1289

75. Freemantle N (2005) How well does the evidence on pioglitazone back up researchers' claims for a reduction in macrovascular events? BMJ 331:836-838

76. Yudkin JS, Freemantle N (2006) PROactive study. Lancet 367:24 25

77. Wang TD, Chen WJ, Cheng WC, Lin JW, Chen MF, Lee YT (2006) Relation of improvement in endothelium-dependent flowmediated vasodilation after rosiglitazone to changes in asymmetric dimethylarginine, endothelin-1, and C-reactive protein in nondiabetic patients with the metabolic syndrome. Am J Cardiol 98:1057-1062

78. Shoelson SE, Lee J, Goldfine AB (2006) Inflammation and insulin resistance. J Clin Invest 116:1793-1801 